\title{
Perceptions of Students and Parents on the Use of Corporal Punishment at Schools in India
}

\author{
Arijit Ghosh $^{1} \&$ Dr. Madhumathi Pasupathi ${ }^{2}$ \\ ${ }^{1,2}$ Assistant Professors in the Department of English, VIT University, Vellore, Tamil Nadu, India. \\ ORCID Ids: oooo-0oo1-9424-8223 E oooo-0001-7751-4470. Email: arijit2net@gmail.com
}

Received June 02, 2016; Revised July 21, 2016; Accepted July 28, 2016; Published August 18, 2016

\begin{abstract}
Violence against children is continuing in schools across India in spite of the strict laws against the use of Corporal Punishment (CP) at schools. The purpose of this study is to identify the reasons for the perpetration of corporal punishments at a random selection of Indian schools as experienced by the students. The population of the sample is small but and the result may be indicative and at the same time may not reflect the condition in the whole of India. The study focuses on the notions of violence within family and the actions of violence which are socio-culturally judged as acceptable in the form of CP at school.-The findings show that students moderately approve violence in the form of CP at schools. The findings also suggest that perceived parental approval of $\mathrm{CP}$ highly influenced the children to psychologically adjust and approve the violence at schools. The study further suggests the need to strengthen the bonds of trust among parents-child relationships in order to curb the menace of $\mathrm{CP}$ at schools.
\end{abstract}

Keywords: Corporal Punishment; Indian students; SPCP; parent-child relationship; child abuse

\section{Introduction}

There is strong relation between violence and power. Michael Foucault, while rethinking upon the history of systems of thought discusses how understandings of violence, sexuality, and power and their interfaces kept on changing over time. Offering a micro-logical view, he explained how during the course of history, 'body' as a site of sexuality and 'self was understood and ideologically constructed in and through discourse, and how inflicting violence on the 'other' has been both justified and opposed depending upon the contexts concerning construction of power and its social structures like colonial, patriarchal, feminist, postcolonial and class related categories (Foucault, 1982). Off late, Derrida's insights about deferral of meaning [and difference] have also been used in rethinking sexuality, violence, and power within their interfaces, as it is considered that these are social constructions which keep on deferring or postponing their meanings that seem to fall back upon endless chains of unreliable inter-texts/signifiers supposedly affixed to them.

Corporal punishment (CP) as an act against children has been widely opposed by various organizations, welfare institution and governments around the world. India is nowhere excluded in creating policies to stop the act of corporal punishment against children in the society. The

(c) AesthetixMS 2016. This Open Access article is published under a Creative Commons Attribution Non-Commercial 4.0 International License (http://creativecommons.org/licenses/by-nc/4.o/), which permits non-commercial re-use, distribution, and reproduction in any medium, provided the original work is properly cited. For citation use the DOI. For commercial re-use, please contact editor@rupkatha.com. 
National Policy on Child Education reports that no child is allowed to be punished or mentally harassed to impart discipline or in order to enhance academic success. Any type of act of violence that inflicts physical or mental pain even without visible external injury on a child is accounted as corporal punishments ("Protection of Children against Corporal Punishment in Schools and Institutions," 2008). However despite all laws and preventive measure $\mathrm{CP}$ continues to be a rampant practice in India In 2010, Ministry of Women and Child Development (MWCD) issued guidelines for teachers instructing to altogether stop practice of using $\mathrm{CP}$ at schools . Laws were made which prescribed punishment such as monetary fine and imprisonment for three years or both for any teacher convicted of using CP at school. ("The Juvenile Justice (Care and Protection of Children) Act, 2015," 2016).

In India corporal punishment is still practiced, even after serious law against the use of corporal punishment, as a traditional method to correct children's behavior or to improve their academic success at schools. It has been noted that “... getting lower percentage of marks in school examination and having a father with low level of education significantly increased the risk of being physically punished by the parents" (Malhi, P \& Ray, M, 2004). Straus (2001) in terms of American students explains that corporal punishment which is considered as an act to correct the child's behavior has served as a possible factor to affect child's well-being and create many problems. It results in many kinds of psychological and behavioral disorders like anxiety, depression, withdrawal, impaired self-concept, impulsivity, delinquency, substance abuse, and maladjustment (Agnew, 1983; Zolotor, A. J, Theodore, A. D., Runyan, D. K., Chang, J. J., \& Laskey, A. L. (2011); Holmes and Robins, 1987, 1988; McCord, 1988).

Studies show that the acceptance of corporal punishment in childhood results in higher rates of criminal activity, perpetration of partner assault, abuse against one's own children and depression (Straus, 2001; Gershoff, 2002). National Policy on Child Education (2013) reports more than $70 \%$ of the students at schools is experiencing corporal punishments. Indian parents are more tolerant towards corporal punishment and conventionally believe that mild CP is necessary for disciplining their children (Douglas, 2006).

Thus, it becomes necessary to identify the factors which are influencing the acceptance of the corporal punishment by students at school. It is also essential to analyse the types of punishment to understand the harshness in the levels of punishments received by the students in Indian schools. It helps to decide on the prevention and intervention efforts required to change the existing attitude towards corporal punishments.

\section{Review of Literature}

In Indian culture, teachers are placed in the same rank with that of the gods. Therefore, it is often believed with all seriousness that the guru (i.e., teacher) needs to be worshiped and obediently served as per the popular ancient Guru Mantra which states, "Gurur Brahma, Gurur Vishnu, Gurur Devo Maheshwarah, Gurur Saakshaat Para-Brahma, Tasmai Shri Guruve Namah.” It means the Guru (teacher) is Brahma (The God of Creation), the Guru is Vishnu (The God of Sustenance), the Guru is Shiva (The God of Annihilation), I bow and salute to such a Guru (teacher), who is verily the Supreme God (trans.by Vedananda, 1993). Veneration of the teacher to the level of God puts them to the place of extremely high power and authority, and such unchecked power runs the risk of executing violence because their moral positions are never questioned in the society.

Researchers have revealed that positive parental attitude toward CP is a significant predictor for its use with children (Durrant, Rose-Krasnor, and Broberg, 2003; Donnelly and 
Straus, 2005; Pinderhughes, Dodge, Bates, Pettit, \& Zelli, 200o; Crouch and Behl. 200; Taylor, Manganello, Lee and Rice, 2010; Winstok, 2014). The reasons for parental acceptance towards CP have been examined by various researchers. One of the studies inspected whether the violence to which one is exposed throughout upbringing might be associated to later life endorsement of CP and established a significant relationship between experiences of $\mathrm{CP}$ as a child and endorsement rates in adulthood (Bower-Russa, Knutson, \& Winebarger, 2001). It has been also pointed out that $\mathrm{CP}$ acceptance rates have been higher among the young adolescents who experienced $\mathrm{CP}$ as a method of parental discipline (Deater-Deckard, Lansford, Dodge, Pettit, \& Bates, 2003). Moreover, it has been found that the degree to which one receives punishments from parents also affects the acceptance of CP (Ringwalt et al., 1989). In relation to these earlier findings, the current study anticipates that perceived parental acceptance of CP might have a significant influence on the acceptance of CP by the students at schools.

In another study, Jambunathan and Counselamn (2002) have assessed the views regarding the $\mathrm{CP}$ among Indian mothers living in India and Indian mother living in United States. The researchers have identified that Indian mothers living in India favoured CP more than that of the mothers living in United States, despite their singularity of their ethnic heritage. Moreover, many researchers have also identified that $\mathrm{CP}$ implementation may in turn corrode bonds of trust and intimacy amidst parents and children (Van Houten, 1983). It is understood that the greatest disadvantage of using $\mathrm{CP}$ is the gap or trouble that it creates between parent-child relationship (Azrin, 1967; Azrin \& Holz,1966, Durrant, 2008). The pain of CP elicits fear, anxiety and rage in children. When the parents generalize $\mathrm{CP}$ towards their children as a normal way of upbringing, the children tend to distance themselves from their parents out of fear (Saarni, Mumme, \&Campos, 1998; Capps, J. S, 2002).

Harsh corporal punishments are often resulting in adolescents' depressive, symptomatology and distress (McLoyd, Jayaratne, Ceballo, \&Borquez, 1994) even after taking into consideration aspects such as age, gender, family's socioeconomic status as test control (Posner and Vandell, 1994, Turner \& Finkelhor, 1996). There is a study in the Indian context where the researcher explores the crippling experience of $\mathrm{CP}$ in the context of Dalit girls. "Chhadi lage chham chham, vidya yeyi gham gham (the harder the stick beats, the faster the flow of knowledge) is an old Marathi proverb. It refers to the corporal punishment rampantly practised by teachers and parents in order to discipline children and make them memorise their lessons (Paik, 2009, p. 176)". Thus the current study has felt the necessity to identify the types of punishments received by the Indian students at schools because there is a lack of research in the Indian context. The study also tries to understand the distribution of the various levels of acceptance of CP based on variables such as gender, parental income and parental educational level.

\section{Methodology}

The current research quantifies the extent to which culture plays a role in propagating and accepting violence as a just, necessary and convenient means of educating and disciplining the children with the sanction of the family. Here, by culture we mean the general belief system of the majority of people with which they identify themselves. Specifically, Indian identity, which according to Kakar \& Kakar, “... is about 'Indian-ness', the cultural part of the mind that informs the activities and concerns of the daily life of a vast number of Indians as it guides them through the journey of life. The attitude towards superiors and subordinates, ... the web of duties and obligations in family life are all as much influenced by the cultural part of the mind as are ideas 
on the proper relationship between the sexes, or on the ideal relationship with god. (Kakar \& Kakar, 2009, p. 1)".

This study includes 201 participants from various states in India who are pursuing engineering program in India. The researchers have used stratified random sampling method for collecting data. Since the population of the study is academically successful and none of the participants are drop outs, it is interesting to ponder that to what extent the students have negotiated themselves with the cultural moorings and to what extent culture prepares them to psychologically adjust themselves to bear and accept the violence The present research has worked with a small sample, moreover, some important categories in the Indian context such as religion and caste were not taken into consideration. This limitation can be addressed in future research.

The study tries to address the gaps in existing literature in certain aspects; firstly, it accounts the type of punishments received by Indian students at schools. Secondly, it identifies the Students' perception of receiving CP and measures the level of acceptance of CP (with SPCP instrument). Thirdly, it identifies the differences in the perception of the students in receiving $\mathrm{CP}$ based on their gender, parental income and parental educational level.

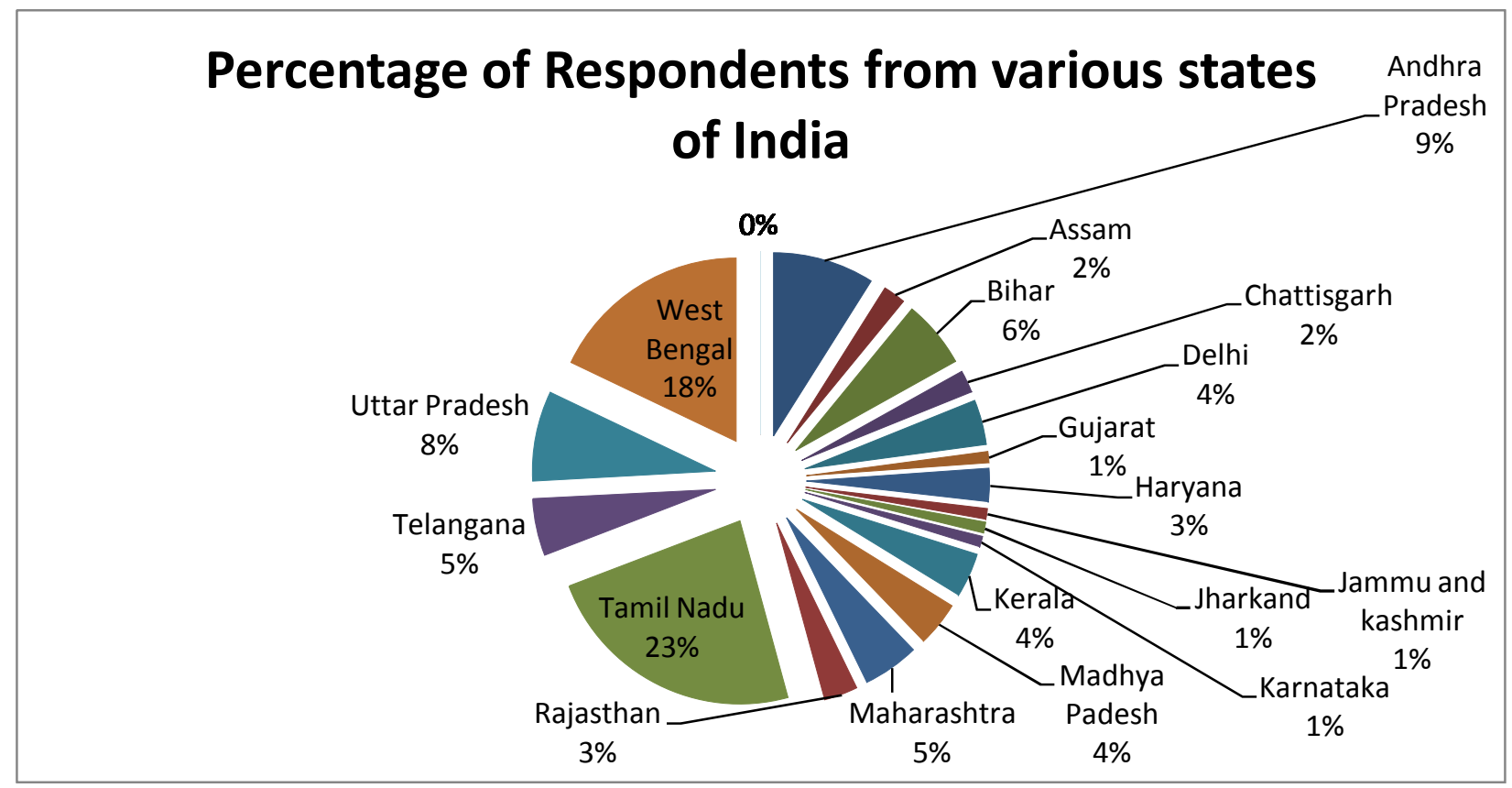

\section{Participants}

The 201 participants from various states in India are pursuing engineering program in a university located in Tamil Nadu, India. More than 20 students from various engineering streams have been randomly chosen for participation in the test. All the students have either directly experienced CP $(70 \%)$ or witnessed it (30\%) in their schools. The exposure of the participants to CP ranges from their primary level to the higher secondary level of their school education ( 3 to 17 years). The participants consist of $73 \%$ male and $27 \%$ females, who have studied either in government or in private schools. The age of the participants ranges from 17 to 19 years. Demographic information 
has been collected through a questionnaire. Interview method has been used with 25 parents to understand the parental acceptance of corporal punishment which has been discussed in the next section. The parents were asked to respond to a set of questions. Some of the questions were: (a) "What is your opinion on the use of CP at School?"; (b) "Do you believe that CP enhances the behavioural and academic achievements of your children?", (c) "Do you think that teacher can unnecessarily punish your children?" (d) "If your child has received corporal punishment from teacher, how will you react for that? Will you patronize or scold your child?".

\section{Instruments}

The researchers have used three sets of questionnaires. SET- A collects demographic details and the responses for general questions on CP (which is discussed in the results section). SET- B consist of Student Perception of Corporal Punishment (SPCP) questionnaires which has three categories of perception such as cultural views of students on $\mathrm{CP}$, perceived parental views of students on $\mathrm{CP}$ and personal views of students on $\mathrm{CP}$.

Cultural Views Questionnaire (CVQ) is a self-report measure that provides information about student's cultural perception on receiving $\mathrm{CP}$ and it helps to measure the level of acceptance of CP based on the influence of culture.

Perceived Parental Views Questionnaire (PPVQ) is a self-report instrument that provides information about student's perceived parental perception about receiving $\mathrm{CP}$. It helps to measure the level of acceptance of $\mathrm{CP}$ by the students based on anticipated approval of parents in receiving $\mathrm{CP}$ at schools.

A Personal Views Questionnaire (PVQ) is a self-report measure that provides information about student's personal perception on receiving $\mathrm{CP}$ at schools. It helps to measure the level of acceptance of CP based on their psychological adjustment.

The SPCP questionnaire consist of 13 questions which are measured in a 3-point Likert type scale ( 3 - highly, 2 - moderately, 1 - not at all). The average scores of the questions represents the levels of acceptance of $\mathrm{CP}$ in which those average of the responses that ranges between 2.5 to 3 unit score indicates high level of acceptance of CP; the average of the responses ranging from 1.5 to 2.49 unit indicates moderate level of acceptance of $\mathrm{CP}$; the average lower than 1.5 unit indicates low level of acceptance of CP.

Set- $C$ consists of 6 questions which have been used to interview the parents. It has been used to understand the perception of the parents about their children receiving $\mathrm{CP}$ at schools. This further validates the students' perception on anticipated approval of parents in receiving CP at schools. The parents were asked to respond to a set of 6 questions: (a) "What is your opinion on the use of CP at School?"; (b) "Do you belive that CP enhances the behavioural and academic achievements of your children?", (c) "Do you believe that teacher can unnecessarily punish your children?" (d) "If your child has received corporal punishment from teacher, how will you react for that? Will you patronize or scold your child?".(e) "Have your child shared his/her daily happenings at school with you?; (f) What is your opinion on the Guru Mantra?

\section{Data analysis and results}

The reliability of the SPCP instrument has been tested with Cronbach's alpha values. The alpha value of the instrument is 0.76 , which indicates an acceptable reliability. Thus, the test results 
indicate that the instrument SPCP, designed for analyzing the level of acceptance of $\mathrm{CP}$ among students taking account of their perception is a reliable instrument. Descriptive statistics and paired sample t-test has been used to compare the significant differences between the mean values of the three categories of perception on CP (personal, perceived parental and cultural). One way -ANOVA has been performed through SPSS software, to identify the significant difference between the perception on receiving $\mathrm{CP}$ at schools based on the gender, parental income, and parental education level. In addition, percentages of different types of punishments encountered by the students have also been recorded. However, religion and caste of the students have not been taken into account, which could be a limitation of the study.

The results of the general questions and SPCP questionnaires have been quantified and discussed below. The question on 'I have received CP at school' unveils that $70 \%$ of the students have reported that they have received corporal punishment at schools. For the question on 'I have seen my classmates getting severely injured by the beating received from teacher to the extent that they fainted or needed hospitalization', $25 \%$ of the students states that they have witnessed such situations and $7 \%$ have had actually experienced such severe beating. Around $43 \%$ of the students felt insecure while receiving the beating. The study has also identified and listed the types of punishments that the students have received at schools (Table 1).

Table 1: Type of punishment and percentage of students' received the punishment

\begin{tabular}{|l|l|}
\hline Type of Punishment & $\begin{array}{l}\text { Percentage of } \\
\text { Students' received }\end{array}$ \\
\hline Scolding & 67 \\
\hline Ear pulling & 56 \\
\hline Beating with hands & 49 \\
\hline Slapping (beating on cheeks) & 48 \\
\hline Asked to kneel-down & 45 \\
\hline Beating with a stick, cane & 43 \\
\hline Hands-above-the head & 42 \\
\hline Sit ups & 39 \\
\hline Palming (beating on palm with stick) & 35 \\
\hline Smacking (Hitting the buttocks with stick) & 23 \\
\hline Verbal abuse & 23 \\
\hline Chair positions (standing in the half squat position for & 20 \\
\hline long time) & 20 \\
\hline $\begin{array}{l}\text { Penciling (Keep a pencil between two fingers and } \\
\text { twisting) }\end{array}$ & 20 \\
\hline Running & 17 \\
\hline Stand in the Sun & 17 \\
\hline Teacher torn notebooks & 16 \\
\hline Threatening & 14 \\
\hline Beating with fist & 10 \\
\hline Standing on one leg for a long time & 10 \\
\hline Rooster position & 8 \\
\hline Stand on one leg with the nose touching the wall & 7 \\
\hline Othersi & 7 \\
\hline
\end{tabular}




\begin{tabular}{|l|l|}
\hline Beating with a footwear & 3 \\
\hline Beating with a rubber belt & 1 \\
\hline
\end{tabular}

1 Others includes teasing by teacher, removing the shirt, fighting with others

Scolding (67\%) and ear pulling (56\%) are the highly received punishment by the students at schools. About (23\%) of the students have reports that they have experienced verbal abuse at schools. It is evident that the students have experienced not only physical punishment but also mental harassment at schools. Even though punishments such as beating with footwear (3\%), removing shirt $(1 \%)$, rooster positions $(8 \%)$, threatening $(14 \%)$, and beating with fist (10\%) were experienced by less percentage of students, the severity involved in receiving these punishments needs to be understood. Some of the students have remarked that teasing and scolding extremely hurt compared to physical punishments. In Indian schools teachers seem to scold the students more often compared to physical punishments.

Table 2: Descriptive Statistics and paired sample t-test for three categories of SPCP questionnaire

\begin{tabular}{|l|l|l|l|l|}
\hline & Mean & Std. D & Difference & T \\
\hline CV & 2.06 & .36 & CV $<$ PPV & $-5.71^{* *}$ \\
\hline PPV & 2.32 & .36 & CV $>$ PV & $9.07^{* *}$ \\
\hline PV & 1.66 & .49 & PPV $>$ PV & $13.34^{* *}$ \\
\hline Total & $\mathbf{2 . 0 2}$ & .31 & & \\
\hline
\end{tabular}

p<o.o1; Cultural View (CV), Perceived Parental View (PPV); Personal View (PV)

Results of the SPCP have reported (Table 2) overall moderate level of psychological acceptance of students in receiving $C P(m=2.02)$. Among the three categories of SPCP questionnaires, it is found that perceived parental views $(\mathrm{m}=\mathbf{2 . 3 2})$ has the higher mean value than that of personal views $(m=1.66)$ and Cultural views $(m=2.06)$. Students strongly $(m=2.69)$ believe that their parents expect them to be respectful and obedient to the teachers. The students moderately $(\mathrm{m}=\mathbf{2 . 3 0})$ fear that their parents will scold or beat them if they say about their corporal punishment at schools. The questions on " $\mathrm{CP}$ helps to complete my homework" and " $\mathrm{CP}$ motivated to be disciplined" reported lowest mean value such as $(\mathrm{m}=1.46)$ and $(\mathrm{m}=1.44)$ respectively. Thus, Indian children almost never felt that corporal punishment helped them to be disciplined or finish their homework; rather it created insecurity in their minds. However, the children have psychologically accepted their punishments because they feared that their parents will beat or scold them if they oppose the teacher. There is no significant difference in perception of $\mathrm{CP}$ based on gender (Table 3).

Table 3: Results of Descriptive Statistics and ANOVA for Gender

\begin{tabular}{|l|l|l|l|l|l|}
\hline & Male & Female & F & Sig. & Difference \\
\hline CV & 2.06 & 2.08 & .053 & .819 & F \\
\cline { 1 - 5 } PPV & 2.29 & 2.39 & 1.390 & .241 & \multirow{2}{*}{ M } \\
\hline PV & 1.62 & 1.78 & 2.127 & .148 & \multirow{1}{*}{} \\
\hline Total & 1.99 & 2.08 & 1.68 & .197 & \\
\hline
\end{tabular}

Cultural View (CV), Perceived Parental View (PPV); Personal View (PV)

For a question seeking cultural view on the ancient Guru Mantra, the results reflect different perceptions based on gender. It is assumed that in India culturally teachers occupy a very high position of admiration for a student, almost equivalent to that of God. There was a significant difference among the male and female students for the question on Guru Mantra', which asked that to what extent they approve to the idea proposed in the Guru Mantra. Results show that 
female students are most likely to approve the ancient saying compared to the male students. Thus, there seems to be a difference of opinions in values added to the cultural beliefs on Guru Mantra based on gender. The result supports idea about the condition of women in India where India“... continues to be a patriarchal society, with the general subordination of women and their disempowerment that patriarchy normally entails (Kakar \& Kakar, 2009, p. 41).”

Low annual income parents' children $(m=2.22)$ tend to feel that their parents strongly support CP as ingrained in the cultural practice in comparison to other income group parents' children (Table 4). This results on the students' perceived parental views on CP from low income group parents $(m=2.65)$ which is similar to the results of other studies (Posner and Vandell, 1994). Economically rich parents' children have low personal acceptance to CP (1.42), which depicts that there are significant difference among the students' perception on Corporal Punishment based on their economic status.

Table 4: Results of Descriptive Statistics and ANOVA for Parental Incomes

\begin{tabular}{|c|c|c|c|c|c|c|c|}
\hline & 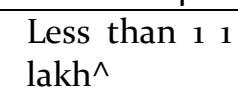 & $\begin{array}{l}1 \text { to } 3 \\
\text { lakhs }{ }^{\wedge}\end{array}$ & $\begin{array}{l}3 \text { to } 5 \\
\text { lakhs }^{\wedge}\end{array}$ & $\begin{array}{ll}\text { above } & 5 \\
\text { lakhs }^{\wedge}\end{array}$ & $\bar{F}$ & Sig. & Difference \\
\hline $\mathrm{CV}$ & 2.22 & 1.93 & 2.13 & 2.01 & 3.51 & $.01^{*}$ & \multirow{4}{*}{$\begin{array}{l}\text { Less than } \\
\text { 1 lakh > } \\
\text { 1-3,3-5\& } \\
\text { above } \\
\text { lakhs }\end{array}$} \\
\hline PPV & 2.65 & 2.29 & 2.31 & 2.11 & 7.06 & $.00^{*}$ & \\
\hline PV & 1.89 & 1.57 & 1.68 & 1.42 & 3.00 & $.03^{*}$ & \\
\hline Total & 2.25 & 1.93 & 2.04 & 1.84 & 6.77 & $.00^{*}$ & \\
\hline
\end{tabular}

Children of the graduate parents have shown comparatively low acceptance $(\mathrm{m}=1.44)$ to receiving $\mathrm{CP}$ at schools, which is reflected in all the three categories influencing the approval of CP (Table 5). The children of a non-graduate parents believe that their parents $(\mathrm{m}=2.43)$ will not support or help them from escaping corporal punishment. The results depicts that Parental education plays a vital role in influencing the student's acceptance towards corporal punishments and the upbringing of the children. Thus, the result elicits the importance of educating the nongraduate parents in these issues related to $\mathrm{CP}$.

Table 5: Results of Descriptive Statistics and ANOVA for Parental Educational Level

\begin{tabular}{|c|c|c|c|c|c|}
\hline & Graduate & $\begin{array}{l}\text { Not a } \\
\text { Graduate }\end{array}$ & $\mathrm{F}$ & Sig. & Difference \\
\hline CV & 2.01 & 2.22 & 6.67 & $.01^{*}$ & \multirow{4}{*}{$\begin{array}{l}\text { Not a } \\
\text { graduate } \\
> \\
\text { Graduate }\end{array}$} \\
\hline PPV & 2.28 & 2.43 & 3.25 & $.05^{*}$ & \\
\hline PV & 1.44 & 2 & 19.92 & $.00^{*}$ & \\
\hline Total & 1.91 & 2.21 & 16.58 & $.00^{*}$ & \\
\hline
\end{tabular}

${ }^{*}$ P > 0.05; Cultural View (CV), Perceived Parental View (PPV); Personal View (PV)

\section{Discussion}

The findings of the study show that students feel helpless when they face $\mathrm{CP}$ and therefore accept the punishment administered by the teacher. They feel that their parents will punish them if they resist punishment at school. In the interview parents have revealed that they sometimes 
knowingly expose their children to such violence. Most of the parents imagine that their child will be disciplined or will academically excel only if their children receive CP at schools. Similarly, the students also agreed that the fear of punishment to certain extent motivate them to complete their academic works. In the interview, most of the Indian parents have reported that 'they believe that the teacher will not punish their children unnecessarily', and so they accept the teachers' punishment against their children on disciplinary grounds. Some parents feel that the teacher has every right to punish their children even if they have passed the exams but got less marks. They consider that $\mathrm{CP}$ is necessary in order to enhance their scores in the forthcoming examinations. It is the lack of interference of the parents in issues related to schools and their belief in age old customs that permits and perpetuates the violence against the children at schools, though legally not sanctioned. Thus, the study affirms that approval of CP is directly linked to culture which clearly signals that the people involved in antiviolence campaigns must focus on the cultural dimensions associated with CP to make their efforts fruitful.

Results indicate that students have psychologically adjusted and accepted their punishment at schools due to lack of parental support in this issue of CP. Many students find themselves helpless in addressing the issue of corporal punishment to their parents. They imagine that their parents will support only the teachers and would not listen to their problems. The students feel that their teachers are powerful in front of their parents than themselves. Therefore, they hide the violence that happens in the schools from their parents. It obviously erodes the bonds of trust and closeness between the parents -child relationship.

Students find their rich and educated parents are more supportive and powerful than their teachers and so to certain extent tend to disclose the violence they experience at schools with the hope that their parents will support them to escape out of it. However, it is interesting to note that parents who are well educated (graduate in this case) and have higher income have less faith on $\mathrm{CP}$ as a positive enforcement technique to bring about any behavioral change. Gender has no significant difference among the perception of students receiving corporal punishments.

\section{Suggestions and conclusion}

The study identifies that perceived parental acceptance of corporal punishment plays a major role in the children's acceptance of corporal punishment at school. Moreover, it creates distance in the child-parent relationship as the children feel that their parents are not in their support to stop the violence they face at schools. Thus, the conventional thinking of parents on children receiving $\mathrm{CP}$ not only corrodes the bond of trust between parent and child, but also facilitates the continuation of violence on children at schools.

The following suggestions can be helpful to curb CP:

- Parents and teachers can learn anger management techniques such as way to calm themselves in an event of tantrum at school and home.

- Parents can interact with their children regarding the daily happenings at school and provide emotional support in all events so that a bond of trust is created.

- Teachers need to be good listener and learn to assert themselves by expressing their feeling directly and calmly without being offensive.

- Instances of CP should be brought to the notice of the school administration by the parents. 
To put in a word, irrespective of national policies on eradication of $\mathrm{CP}$, the violence on children continues. The results show that students receive severe punishments in schools which are psychologically and physically affecting them. The lack of support from the parents is the major reason for psychological acceptance of $\mathrm{CP}$ at schools. The result shows that students who belong to the socioeconomically weaker sections and whose parents are not highly educated believe more on the effectiveness of CP. The students of the relatively weaker background tend to suffer more; they are colonized at home by their parents and at school by teachers. Students who often receive $\mathrm{CP}$ start believing that violence is part and parcel of schooling. Thus violence becomes naturalized in the psyche of the children as a just method of communication beyond words when one wants to exercise power and authority over others.

\section{Note}

\footnotetext{
${ }^{\mathrm{i}}$ The Guru Mantra occurs in the Brahma Vaivarta Purana, an ancient Indian text. Even without reading the Purana a large section of the people in India know the mantra in parts or in whole. Almost all the participants in this research could recognise the mantra if they did not know its source. They have heard it before, either in school, or in recording of devotional songs in various languages beside temples.
}

\section{References}

Agnew, R. (1983). Physical Punishment and Delinquency:" A Research Note". Youth and society, 15(2), 225.

Arnold, E. (1982). The use of corporal punishment in child rearing in the West Indies. Child abuse E neglect, 6(2), 141-145.

Azrin, N. (1967). Pain and aggression. Psychology Today, 1, 27-33.

Azrin, N. H., \& Holz, W. C. (1966). Punishment. Operant behavior: Areas of research and

application, 380-447.

Bower-Russa, M. E., Knutson, J. F., \& Winebarger, A. (2001). Disciplinary history, adult disciplinary attitudes, and risk for abusive parenting. Journal of Community Psychology, 29(3), 219-240

Crouch, J. L., \& Behl, L. E. (2001). Relationships among parental beliefs in corporal punishment, reported stress, and physical child abuse potential. Child Abuse \& Neglect, 25(3), 413-419..

Capps, J. S. (2002). Explaining punitiveness: Right-wing authoritarianism and social dominance. North American Journal of Psychology, 4, 263-278.

Danso, H., Hunsberger, B., \& Pratt, M. (1997). The role of parental religious fundamentalism

and right-wing authoritarianism in child-rearing goals and practices. Journal for the Scientific Study of Religion, 496-511.

Deater-Deckard, K., Lansford, J. E., Dodge, K. A., Pettit, G. S., \& Bates, J. E. (2003). The

development of attitudes about physical punishment: An 8-year longitudinal study. Journal of Family

Psychology, 17(3), 351.

Donnelly, M., \& Straus, M. (Eds.). (2008). Corporal punishment of children in theoretical

perspective. Yale University Press. 
Douglas, E. M. (2006). Familial violence socialization in childhood and later life approval of corporal punishment: A cross-cultural perspective. American Journal of Orthopsychiatry, 76(1), 23-30.

Durrant, J. E. (2008). Physical punishment, culture, and rights: current issues for professionals. Journal of Developmental \& Behavioral Pediatrics, 29(1), 55-66.

Durrant, J. E., Rose-Krasnor, L., \& Broberg, A. G. (2003). Physical punishment and maternal beliefs in Sweden and Canada. Journal of Comparative Family Studies, 585-604.

Foucault, M. (1982). The Subject and Power. Critical Inquiry, 8(4), 777-795.

Flynn, C. P. (1994). Regional differences in attitudes toward corporal punishment. Journal of Marriage and the Family, 314-324.

Gershoff, E. T. (2002). Corporal punishment by parents and associated child behaviors and experiences: a meta-analytic and theoretical review. Psychological bulletin, 128(4), 539.

Holmes, S. J., \& Robins, L. N. (1987). The influence of childhood disciplinary experience on the development of alcoholism and depression. Journal of Child Psychology and Psychiatry, 28(3), 399-415.

Jambunathan, S., \& Counselman, K. (2002). Parenting attitudes of Asian Indian mothers living in the United States and in India. Early Child Development and Care, 172(6), 657-662.

Kakar, S., \& Kakar, K. (2009). The Indians: Portrait of a People. Penguin Books India.

Malhi, P., \& Ray, M. (2004). Prevalence and correlates of corporal punishment among adolescents. Studia Psychologica, 46(3), 219-228.

McCord, J. (1988). Parental behavior in the cycle of aggression. Psychiatry, 51(1), 14-23.

Paik, S. (2009). Chhadi Lage Chham Chham, Vidya Yeyi Gham Gham (The Harder the Stick Beats, the Faster the Flow of Knowledge): Dalit Women's Struggle for Education. Indian Journal of Gender Studies, 16(2), 175-204.

Pinderhughes, E. E., Dodge, K. A., Bates, J. E., Pettit, G. S., \& Zelli, A. (2000). Discipline responses: influences of parents' socioeconomic status, ethnicity, beliefs about parenting, stress, and cognitiveemotional processes. Journal of family psychology, 14(3), 380 .

Posner, J. K., \& Vandell, D. L. (1994). Low-Income Children's After-School Care: Are There Beneficial Effects of After-School Programs?. Child development, 65(2), 440-456.

Protection of Children against Corporal Punishment in Schools and Institutions. (2008, December). National Commission for the Protection of Child Rights. Retrieved from http://harprathmik.gov.in/pdf/rte/corporal\%2opunishment\%2oncpcr.pdf

Ringwalt, C. L., Browne, D. C., Rosenbloom, L. B., Evans, G. A., \& Kotch, J. B. (1989). Predicting adult approval of corporal punishment from childhood parenting experiences. Journal of Family Violence, 4, 339-351.

Rohner, R. P. (1986). The warmth dimension: Foundations of parental acceptance-rejection theory. Sage Publications, Inc.

Saarni, C., Campos, J. J., Camras, L. A., \& Witherington, D. (1998). Emotional development: Action, communication, and understanding. Handbook of child psychology.

Straus, M. A. (2001). Beating the devil out of them: Corporal punishment in American families and its effects on children. Transaction Publishers.

Straus, M. A. (1998). Corporal punishment of children and adult depression and suicidal ideation. Coercion and punishment in long-term perspectives, 59-77. 
Taylor, C. A., Manganello, J. A., Lee, S. J., \& Rice, J. C. (2010). Mothers' spanking of 3-year-old children and subsequent risk of children's aggressive behavior. Pediatrics, 125(5), 1057-1065.

The Juvenile Justice (Care and Protection of Children) Act, 2015. (2016, January 1). The Gazette of India.Retrieved from http://trackthemissingchild.gov.in/trackchild/readwrite/JJAct_2015.pdf

The National Policy for Children, 2013. (n.d.). Retrieved June 15, 2016, from

http://www.childlineindia.org.in/The-National-Policy-for-Children-2013.htm

Turner, H. A., \& Finkelhor, D. (1996). Corporal punishment as a stressor among youth. Journal of Marriage and the Family, 155-166.

Van Houten, R. (1983). Punishment: From the animal laboratory to the applied setting. The effects of punishment on human behavior, 13-44.

Vedananda, S. (1993). Aum Hindutvam: (daily Religious Rites of the Hindus). Motilal Banarsidass Publisher.

Winstok, Z. (2014). Israeli Mothers' willingness to use corporal punishment to correct the misbehavior of their elementary school children. Journal of interpersonal violence, 29(1), 44-65.

Wissow, L. S. (2001). Ethnicity, income, and parenting contexts of physical punishment in a national sample of families with young children. Child maltreatment, 6(2), 118-129.

Zolotor, A. J., Theodore, A. D., Runyan, D. K., Chang, J. J., \& Laskey, A. L. (2011). Corporal

punishment and physical abuse: population-based trends for three-to-11-year-old children in the United States. Child abuse review, 20(1), 57-66. 